\title{
Genomic-based tools for the risk assessment, management, and prevention of type 2 diabetes
}

\author{
This article was published in the following Dove Press journal: \\ The Application of Clinical Genetics \\ 7 January 2015 \\ Number of times this article has been viewed
}

\section{Katherine A Johansen Taber Barry D Dickinson}

Department of Science and Biotechnology, American Medical Association, Chicago, IL, USA
Correspondence: Katherine A Johansen Taber

Department of Science and

Biotechnology, American Medical

Association, $330 \mathrm{~N}$ Wabash Ave, Suite

39300, Chicago, IL 606 I I, USA

Tel +I 3124644964

Email katherine.johansen@ama-assn.org
Abstract: Type 2 diabetes (T2D) is a common and serious disorder and is a significant risk factor for the development of cardiovascular disease, neuropathy, nephropathy, retinopathy, periodontal disease, and foot ulcers and amputations. The burden of disease associated with T2D has led to an emphasis on early identification of the millions of individuals at high risk so that management and intervention strategies can be effectively implemented before disease progression begins. With increasing knowledge about the genetic basis of T2D, several genomicbased strategies have been tested for their ability to improve risk assessment, management and prevention. Genetic risk scores have been developed with the intent to more accurately identify those at risk for T2D and to potentially improve motivation and adherence to lifestyle modification programs. In addition, evidence is building that oral antihyperglycemic medications are subject to pharmacogenomic variation in a substantial number of patients, suggesting genomics may soon play a role in determining the most effective therapies. T2D is a complex disease that affects individuals differently, and risk prediction and treatment may be challenging for health care providers. Genomic approaches hold promise for their potential to improve risk prediction and tailor management for individual patients and to contribute to better health outcomes for those with T2D.

Keywords: diabetes, genomic, risk prediction, management

\section{Introduction}

Type 2 diabetes (T2D) is a complex disease characterized by insulin resistance, impaired insulin secretion, and increased hepatic glucose production. It is a common disorder: more than 29 million people in the US have T2D, and nearly three times that number are at risk of developing the disease. ${ }^{1}$ Risk factors for T2D include obesity, physical inactivity, advancing age, hypertension, hyperlipidemia, and a family history of T2D. Dozens of genetic variations have been identified that also increase risk. ${ }^{2}$ The progression and severity of T2D in any given individual is dependent on the combination of risk factors, both genetic and nongenetic, that he or she exhibits. ${ }^{3}$ Complications of T2D include cardiovascular disease, stroke, neuropathy, nephropathy, retinopathy, periodontal disease, and foot ulcers and amputations.

The serious burden of disease associated with T2D has led to an emphasis on early identification of individuals at high risk so that management and intervention strategies can be effectively implemented before disease progression has begun. Clinical factors such as body mass index (BMI; a measure of overweight and obesity), age, and family history are most often used in predicting T2D risk, and treatment strategies initially tend to be the same for most individuals. However, the complexity underlying individual 
risk, disease progression, and therapeutic response may limit the effectiveness of such standardized risk prediction and therapeutic approaches. Indeed, eight million people in the US are thought to be undiagnosed, and 86 million people in the US exhibit signs of prediabetes (blood glucose levels higher than normal but below diagnostic levels for diabetes). ${ }^{1}$ In addition, most people diagnosed with T2D will eventually require more than one pharmacologic treatment to achieve glycemic control.

The identification of genetic variants that increase risk for T2D has led to the hypothesis that risk prediction and treatment could become more precise by including genomic factors in risk assessment, management, and prevention strategies. Tools using genomic information to predict those who are at risk and to tailor pharmacologic and lifestyle modification therapies have been developed and tested, with varying degrees of success and promise. This review briefly summarizes recent advancements in the application of genomics to the clinical care of T2D.

\section{Genetic risk factors for type 2 diabetes}

A very small percentage (1\%-2\%) of diabetes cases, often misdiagnosed as T2D, are monogenic, resulting from mutations in a single gene. In contrast, dozens of gene variants contribute to increased risk for T2D. Rapidly advancing techniques in DNA sequencing and genetic analysis have led to the identification of more than 65 genetic variations that increase risk for T2D. ${ }^{4}$ Many of these variants are thought to affect insulin secretion by impairing the function of beta cells, rather than affecting insulin action in tissues. ${ }^{5}$ The majority of identified genetic variations increase T2D risk by approximately $10 \%-45 \% ;^{3}$ however, individuals carrying homozygous copies of certain risk alleles face much higher risk than do noncarriers. For example, risk for T2D in homozygous carriers of a variant in the gene TBC1D4 is about ten times higher than that for noncarriers. ${ }^{6}$ For comparison, risk factors such as obesity, hypertension, and hyperlipidemia increase risk by approximately two to six times. ${ }^{7}$ Table 1 lists the relative risk associated with identified genetic variations, as well as that associated with other common risk factors.

The contribution of genetic factors to diabetes risk, onset, and progression is estimated to be as high as $40 \%$, but that number is highly variable from person to person. ${ }^{8}$ Research into the genetic factors that increase risk for T2D has reinforced the concept that T2D is a complex disease characterized by a unique combination of genetic variants, clinical risk factors, and behavior in each individual. In patients meeting
Table I Relative risk associated with type 2 diabetes risk factors

\begin{tabular}{ll}
\hline Risk factor & Relative risk \\
\hline Age $\geq 45$ years & $5-6 \times$ \\
Obesity: body mass index $\geq 30 \mathrm{~kg} / \mathrm{m}^{2}$ & $4-5 \times$ \\
Overweight: body mass index $\geq 25,<30 \mathrm{~kg} / \mathrm{m}^{2}$ & $2-3 \times$ \\
Hypertension & $2-3 \times$ \\
Hyperlipidemia & $4 \times$ \\
$\begin{array}{l}\text { Family history } \\
\text { One first-degree relative or two second-degree relatives }\end{array}$ & $2-3 \times$ \\
$\begin{array}{l}\text { Two first-degree relatives, or one first-degree and } \\
\text { two second-degree relatives }\end{array}$ & $5-6 \times$ \\
Genetic variant carrier & \\
Heterozygous & $1.1-1.4 \times$ \\
Homozygous & Up to $10 \times$ \\
\hline
\end{tabular}

Note: Relative risk estimates of overweight and obesity are compared with those with body mass index $<25 \mathrm{~kg} / \mathrm{m}^{2}$. Data from. ${ }^{3,6,7,16}$

the diagnostic criteria of $\mathrm{T} 2 \mathrm{D}$, substantial variability may exist in the genetic variants present and in the amount of risk they confer together, pathogenic mechanisms, and clinical features. ${ }^{3}$ For example, patients with T2D who are younger and leaner (lower BMI or smaller waist circumference) have a stronger genetic predisposition compared with patients with T2D who are older and overweight or obese..$^{9-11}$ Adding complexity to the quantification of genetic contribution to risk is the notion that certain variants confer protection against T2D. ${ }^{12}$ This complexity is further heightened when taking into account genetic variations that are separately associated with T2D risk factors such as obesity, hypertension, and hyperlipidemia. Thus, some portion of genetic risk for T2D is captured by measuring those clinical risk factors. Overlap exists between the genetic and other risk factors for T2D, but questions remain as to their additive effects.

\section{Family history as a risk factor}

Family history is an established risk factor for T2D. For individuals with one or more first-degree relatives diagnosed with $\mathrm{T} 2 \mathrm{D}$, risk is estimated to increase by approximately two to six times. ${ }^{13}$ Concordance studies in identical and fraternal twins have firmly established the genetic heritability of T2D, ${ }^{14}$ but family history has the added capability of revealing both shared genetic factors and environmental factors that families tend to share, such as physical activity and dietary behaviors. Interestingly, the contribution of family history to risk is independent of that conferred by other risk factors. ${ }^{7,15,16}$ For example, having one first-degree relative with T2D doubles the risk of having T2D (Table 1), even after adjusting for other risk factors that may be present, such as hypertension, hyperlipidemia, and obesity. ${ }^{7}$ 
The use of family history as a screening tool to detect undiagnosed diabetes and identify those who may be at increased risk has been evaluated by a number of studies, ${ }^{15-17}$ one of which estimated that a risk prediction model including family history would identify $23 \%$ more undiagnosed cases of T2D than would one without family history. ${ }^{17}$ Accordingly, the most commonly used risk prediction models for T2D include questions about T2D in family members. ${ }^{15}$

\section{Genomic applications in the risk assessment and prevention of type 2 diabetes}

Risk assessment tools for T2D usually include questions about age, sex, ethnicity, hypertension, BMI or weight, family history, and a history of gestational diabetes; some include measurements of biochemical markers such as cholesterol and glucose levels. ${ }^{18}$ Continued discovery of genetic variants contributing to increased risk for diabetes has led to the hypothesis that genetic information beyond that revealed by family history could enhance current risk assessment tools and improve T2D diagnosis and risk stratification.

\section{Genetic risk scores}

Although T2D risk assessment tools based on clinical risk factors typically are quite accurate, genetic tests, both alone and in combination with clinical risk factors, have been evaluated for their ability to improve the accuracy of T2D risk prediction. ${ }^{18,19}$ A number of studies have been undertaken to evaluate the ability of genetic tests to predict the development of T2D. These tests usually are designed to detect several of the genetic variants associated with T2D and include an algorithm that quantifies risk by scoring the number and type of risk alleles present and returning a "genetic risk score" (GRS). A high GRS indicates a high number of risk alleles, and therefore a high risk for T2D. Studies have shown that some GRSs can stratify patients into risk categories and accurately predict those who will develop T2D., ${ }^{9,20-23}$ In a study of participants enrolled in the Diabetes Prevention Program, a high GRS was associated with increased risk of progression to diabetes and a lower probability of regressing to normal glucose regulation, ${ }^{20}$ and in adolescents enrolled in the Bogalusa Heart Study, a GRS significantly predicted the development of T2D in adulthood. ${ }^{22}$ Further, an association between a GRS and cardiovascular disease in patients with T2D was observed even after adjusting for other risk factors, suggesting potential utility for GRSs in predicting health outcomes. ${ }^{24}$
Despite the ability of the GRS to stratify risk and predict progression to $\mathrm{T} 2 \mathrm{D}$ and to potentially predict cardiovascular disease, its clinical use beyond that of phenotypic-based risk prediction models is questionable. When considered along with other phenotypic markers such as blood glucose level and BMI, the GRS appears to provide very limited or no added value to prediction of T2D risk or progression. . $^{21,22,25-30}$ Potentially promising results have been shown in subpopulations, however. In patients younger than 50 years, a GRS modestly improved risk classification even after accounting for other clinical risk factors. ${ }^{9,10,21}$ Similarly, a GRS provides slightly more accurate risk prediction in individuals with a lower BMI, suggesting that assessing genetic variants, which are constant in an individual from conception, may have more clinical utility before the emergence of clinical risk factors that are acquired over time. ${ }^{29}$ Conversely, a GRS slightly improved risk prediction beyond clinical risk factors in patients who are obese or who have a family history of T2D, possibly because it provided a mechanism by which to distinguish the magnitude of risk conferred by known genetic variants otherwise masked by the more prominent risk factors of obesity and family history. ${ }^{25}$ However, these studies have been small, and others have not come to the same conclusions. ${ }^{22,25}$ Several trials examining the potential of GRSs to improve risk prediction and prevention are currently ongoing and may provide refined information on which subpopulations would benefit from use of a GRS.

\section{Genetic risk scores and patient motivation}

A potential of genome-based medicine is to motivate individuals to make personalized lifestyle changes that lessen their disease risk. ${ }^{31,32}$ Patients report a high level of interest in genetic testing for chronic diseases such as T2D. ${ }^{8,33-37}$ Genetic information carries special significance for patients because it is "scientific," "certain," and "durable," which are qualities that patients may not attribute to family history and environmental risk factors. ${ }^{8,38-40}$ Several studies have examined whether the provision of a T2D GRS affects motivation to make lifestyle changes. In patients at high risk for T2D based on phenotypic risk factors, those receiving a hypothetical high GRS report higher motivation to adopt healthier behaviors than those receiving a low GRS. ${ }^{8,37,40,41}$ In patients with T2D, a majority report that a high GRS would lead to better medication adherence. ${ }^{39}$ However, behavior change in response to genetic risk appears to be dependent on patients' baseline motivation levels. Among individuals at increased $\mathrm{T} 2 \mathrm{D}$ risk according to phenotypic risk factors 
such as hypertension and glucose levels, those who are highly motivated report that a hypothetical high GRS would result in further inspiration and that a low GRS would not detract from their behavioral modification goals. ${ }^{8}$ However, those who are less motivated report that they are more likely to use a hypothetical low GRS to justify their decision not to actively pursue lifestyle modifications. ${ }^{8}$ For T2D, these results suggest that the disclosure of genetic test results should include explanations of how genetic risk can be affected by lifestyle and behavior. Studies that continue to reveal the characteristics of those patients who will derive motivation from genetic test results, along with methods of structuring the disclosure of genetic test results to optimize motivational potential, will be valuable.

\section{Genetic counseling and risk communication}

Risk can be communicated to patients in many ways, and using terms that patients understand is important for their perception of personal risk and for promoting positive health outcomes. $^{42}$ Genetic counseling sessions typically involve in-depth conversations about risk and guidance about what different risk levels mean for the patient's health and the health of family members. ${ }^{43}$ It has been suggested that genetic risk counseling as an accompaniment to a GRS can improve prevention efforts and better motivate patients to make lifestyle modifications. A recent study demonstrated that patients were better able to understand the results of a GRS delivered during an in-person genetic counseling session compared with results delivered online with no involvement of a genetic counselor. ${ }^{44}$ In another study, receipt of a GRS followed by a structured genetic counseling session resulted in high-risk patients reporting that they were more motivated than were low-risk patients to participate in a 12 week lifestyle modification program. ${ }^{45}$ However, actual attendance in the lifestyle modification program was not altered, and weight loss was not significantly different among those who received the GRS and genetic counseling compared with those who did not. ${ }^{45,46}$ Short-term results from a different trial have shown small changes in dietary intake and weight loss among participants who received a GRS and genetic risk counseling compared with those who did not; longer-term results have not yet been reported. ${ }^{47}$ Other trials examining different genetic counseling and health coaching approaches to effectively communicate risk with GRSs are currently underway. ${ }^{48-50}$

Genetic counseling for those with a family history of T2D has shown promising potential. In a trial of healthy adults who have more than one first-degree relative with T2D, a brief genetic counseling session that included discussion of the seriousness of T2D, risk factors for T2D, benefits of lifestyle modification in those genetically predisposed, and guidance on specific lifestyle modifications resulted in a significantly higher sense of control over diabetes onset compared with those who did not receive counseling. ${ }^{51}$ It remains to be seen whether the improved sense of control will lead to lifestyle modifications that decrease T2D risk and onset.

\section{Genomic applications in the management of type 2 diabetes}

Although much attention and focus have been devoted to methods for identifying those at risk for T2D and preventing its onset, strategies for optimally managing those patients who have been diagnosed with T2D or identified as at risk are important as well, as complications from T2D can result in significant morbidity. Lifestyle modification consisting of a healthful diet and increase in physical activity, with the goal of reducing body weight, often in the context of a formal program led by a counselor or instructor, is recommended for nearly everyone diagnosed with T2D or at risk of developing it. ${ }^{52}$ In addition, pharmacologic therapy is usually initiated in those with or at risk for T2D. ${ }^{52}$ However, neither lifestyle modification nor pharmacologic therapy is effective in every patient. ${ }^{53-56}$ Advances in the understanding of the genetic control of T2D are contributing to the development of management options that may be individually tailored on the basis of the patient's genotype, and may be potentially more successful.

\section{Pharmacogenomics of T2D therapeutics}

Pharmacologic treatment of T2D is intended to lower blood glucose concentrations and maintain nearly normal hemoglobin A1c levels without inducing hypoglycemia. ${ }^{57}$ Several classes of oral drugs are available to achieve such goals. The preferred first-line agent is usually metformin, a biguanide that decreases hepatic glucose production, intestinal absorption, and to a lesser extent, glucose uptake into peripheral tissues. ${ }^{57}$ Second-line agents of choice tend to be sulfonylureas (eg, glipizide, glyburide) and meglitinides (eg, repaglinide, nateglinide), which directly increase insulin secretion; GLP-1 (glucagon-like peptide-1) receptor agonists such as exenatide; DPP-4 (dipeptidyl peptidase-4) inhibitors (eg, alogliptin, linagliptin); and the alpha glucosidase inhibitor acarbose. ${ }^{57}$ Thiazolidinediones (eg, pioglitazone, rosiglitazone) also are available but are not commonly used because of uncertainty about their cardiovascular risk. ${ }^{57}$ Most patients with T2D eventually require combination therapy, including the use of insulin products. ${ }^{58,59}$ 
Patient response to oral antihyperglycemia drugs can be variable and challenging to predict. No single drug exists that optimally lowers blood glucose levels in all patients, ${ }^{53}$ and nearly $40 \%$ of patients do not reach desired hemoglobin A1c levels while being treated. ${ }^{54}$ The variable and incomplete response to T2D drugs is thought to be partially the result of genetic variations that affect the metabolism of, and response to, the drug. ${ }^{60}$ In some cases, genetic variations may result in increased effectiveness. Patients who carry variants in the gene encoding cytochrome P450 2C9 have decreased sulfonylurea clearance; in response to some sulfonylureas including glipizide, glimepiride, glyburide, and tolbutamide, larger decreases in blood glucose levels and higher 12-hour insulin secretion are observed in variant carriers compared with in patients carrying the most common allele..$^{58,61-65}$ In addition, carriers of certain variants in PPAR $\gamma$, which regulates fatty acid storage and glucose metabolism, show greater decreases in blood glucose and hemoglobin A1c levels in response to rosiglitazone and pioglitazone than do noncarriers. ${ }^{59,66,67}$ Conversely, genetic variants may alter the effectiveness of a medication. For example, a small study showed that carriers of variants that reduce hepatic uptake of metformin show decreased glucose-lowering response to metformin compared with noncarriers, suggesting metformin may not be as effective in variant carriers as in noncarriers. ${ }^{59,68}$ Other studies have not replicated that finding but have shown differences in the pharmacokinetics of metformin with several gene variants. ${ }^{69-71}$ Another potential effect of genetic variants is adverse events. For example, carriers of variants that result in glucose 6-phosphate dehydrogenase (G6PD) deficiency are at risk for hemolytic anemia when taking certain sulfonylureas. Accordingly, the labels of glipizide, glyburide, and chlorpropamide note that prescribers should consider a nonsulfonylurea in G6PD-deficient patients. ${ }^{72-74}$ For the most part, studies on the pharmacogenomics of antihyperglycemic agents have been small, and their results have not yet translated into changes in clinical practice. Nonetheless, they demonstrate the concept that significant variability in patient response to T2D therapeutic agents is a result of genetic variation and reinforce the complexity of choosing the most effective therapies for individual patients.

\section{Genomic predictors of effective intervention strategies}

Almost all patients diagnosed with and at risk for T2D are encouraged to engage in lifestyle modification that includes improvements in diet and increases in physical activity, with the goal of reducing weight and other risk factors such as hypertension and hyperlipidemia. Although lifestyle modification programs are quite successful when taken as a whole, certain approaches appear to be more successful in some patients than in others. ${ }^{55,56}$ Exploration into the genetic factors that might explain which lifestyle modification behaviors are most likely to reduce T2D risk factors for each patient has been undertaken. For example, in patients with T2D who carry a homozygous TCF7L2 variant, blood glucose and lipid levels were lower and stroke risk was attenuated with strict adherence to the Mediterranean diet compared with strict adherence to a low-fat diet. ${ }^{75}$ The two diets were equally effective in noncarriers of the TCF $2 L 2$ variant. ${ }^{75}$ Similarly, in diabetic carriers of certain genetic variants affecting lipid levels, high-density lipoprotein cholesterol levels were increased more after an intensive lifestyle intervention that included caloric restriction and physical activity compared with an intervention that included only diabetes education; noncarriers of the variants did not show such differences in high-density lipoprotein levels in response to either intervention. ${ }^{76}$ In a third trial, patients with prediabetes carrying certain variants associated with obesity showed differences in weight loss and weight regain in response to both metformin and lifestyle interventions compared with noncarriers. ${ }^{77}$ These examples suggest that patient response to lifestyle modification may be partly controlled by the variants they carry and that interventions may be most effective when tailored to individuals according to their genotype. An additional important point demonstrated by these examples is that genetic risk often can be attenuated by effective interventions. ${ }^{20,78}$

\section{Conclusion and future directions}

Genetic factors play a substantial role in the risk, onset, severity, and downstream complications of T2D. Overall, current knowledge about the contribution of genomic factors to $\mathrm{T} 2 \mathrm{D}$ reinforces the concept that $\mathrm{T} 2 \mathrm{D}$ is a complex disease that can be different in every person and that risk prediction and treatment are exceptionally challenging for health professionals. Evidence thus far shows variable clinical utility of GRSs, although certain subpopulations may benefit from their use in the near future, and forthcoming research may improve their utility. In addition, important information is being revealed about the genetic basis for differential therapeutic responses to oral antihyperglycemic drugs and to intervention strategies. Although clinical practice guidelines employing genomic approaches to T2D management and prevention do not yet exist, health professionals should be aware that pharmacogenomic factors may result in varying 
responses to pharmacologic therapy and that the degree of success of weight reduction through lifestyle modification may be partially dependent on genetic factors.

Genomic analysis in clinical care is rapidly advancing, especially with the use of next-generation sequencing technologies and whole-genome sequencing. ${ }^{79} \mathrm{~A}$ small number of studies have employed whole-genome sequencing in healthy patients as a mechanism to identify risk for future disease onset, and two studies have demonstrated the capability of predicting risk for T2D and other chronic diseases. ${ }^{80,81}$ Although the routine clinical use of whole-genome sequencing in patients who appear healthy and asymptomatic is not likely to occur for several years, the studies nonetheless demonstrate the power of the technology and potential future uses. In addition, epigenetic mechanisms such as methylation and histone modification, which often arise as a result of environmental exposures, have recently been examined for their involvement in T2D pathogenesis. Although direct evidence establishing a causal relationship between epigenetic modification and risk for T2D is not yet available, observational and animal studies have suggested that epigenetic alterations in gene expression may play a role. When and if a causal relationship is established, it may be possible to use epigenetic modifications as biomarkers to predict those who may be at increased risk. ${ }^{82,83}$ Considering the significantly variable nature of T2D, both in the genetic and environmental risk factors and in the clinical presentation, the most immediate use of genetic information is likely to be in the characterization of individual cases of T2D, with the goal of improving each patient's outcomes, motivation for long-term lifestyle modification, and therapeutic response.

\section{Acknowledgments}

We thank the members of the American Medical Association Council on Science and Public Health for their review of an early version of this manuscript, as well as Annalynn Skipper for her editorial comments.

\section{Disclosure}

The development of this manuscript was supported by the American Medical Association. The authors report no conflicts of interest in this work.

\section{References}

1. Centers for Disease Control and Prevention. National Diabetes Statistics Report, 2014. Atlanta, GA: Centers for Disease Control and Prevention; 2014. Available from: http://www.cdc.gov/diabetes/pubs/statsreport14/ national-diabetes-report-web.pdf. Accessed December 10, 2014.

2. McCarthy MI. Genomics, type 2 diabetes, and obesity. $N$ Engl J Med. 2010;363(24):2339-2350.
3. Malandrino N, Smith RJ. Personalized medicine in diabetes. Clin Chem. 2011;57(2):231-240.

4. Morris AP, Voight BF, Teslovich TM, et al; Wellcome Trust Case Control Consortium; Meta-Analyses of Glucose and Insulin-related traits Consortium (MAGIC) Investigators; Genetic Investigation of ANthropometric Traits (GIANT) Consortium; Asian Genetic Epidemiology Network-Type 2 Diabetes (AGEN-T2D) Consortium; South Asian Type 2 Diabetes (SAT2D) Consortium; DIAbetes Genetics Replication And Meta-analysis (DIAGRAM) Consortium. Large-scale association analysis provides insights into the genetic architecture and pathophysiology of type 2 diabetes. Nat Genet. 2012;44(9):981-990.

5. Lyssenko V, Laakso M. Genetic screening for the risk of type 2 diabetes: worthless or valuable? Diabetes Care. 2013;36(Suppl 2):S120-S126.

6. Moltke I, Grarup N, Jørgensen ME, et al. A common Greenlandic TBC1D4 variant confers muscle insulin resistance and type 2 diabetes. Nature. 2014;512(7513):190-193.

7. Dallo FJ, Weller SC. Effectiveness of diabetes mellitus screening recommendations. Proc Natl Acad Sci U S A. 2003;100(18): 10574-10579.

8. Markowitz SM, Park ER, Delahanty LM, O'Brien KE, Grant RW. Perceived impact of diabetes genetic risk testing among patients at high phenotypic risk for type 2 diabetes. Diabetes Care. 2011;34(3): 568-573.

9. de Miguel-Yanes JM, Shrader P, Pencina MJ, et al; MAGIC Investigators; DIAGRAM+ Investigators. Genetic risk reclassification for type 2 diabetes by age below or above 50 years using 40 type 2 diabetes risk single nucleotide polymorphisms. Diabetes Care. 2011;34(1):121-125.

10. Langenberg C, Sharp SJ, Franks PW, et al. Gene-lifestyle interaction and type 2 diabetes: the EPIC interact case-cohort study. PLoS Med. 2014;11(5):e1001647.

11. Perry JR, Voight BF, Yengo L, et al; MAGIC; DIAGRAM Consortium; GIANT Consortium. Stratifying type 2 diabetes cases by BMI identifies genetic risk variants in LAMA1 and enrichment for risk variants in lean compared to obese cases. PLoS Genet. 2012;8(5):e1002741.

12. Flannick J, Thorleifsson G, Beer NL, et al; Go-T2D Consortium; T2DGENES Consortium. Loss-of-function mutations in SLC30A8 protect against type 2 diabetes. Nat Genet. 2014;46(4):357-363.

13. Harrison TA, Hindorff LA, Kim H, et al. Family history of diabetes as a potential public health tool. Am J Prev Med. 2003;24(2):152-159.

14. Poulsen P, Kyvik KO, Vaag A, Beck-Nielsen H. Heritability of type II (non-insulin-dependent) diabetes mellitus and abnormal glucose tolerance - a population-based twin study. Diabetologia. 1999;42(2): $139-145$.

15. Valdez R, Greenlund KJ, Khoury MJ, Yoon PW. Is family history a useful tool for detecting children at risk for diabetes and cardiovascular diseases? A public health perspective. Pediatrics. 2007;120(Suppl 2): S78-S86.

16. Valdez R. Detecting undiagnosed type 2 diabetes: family history as a risk factor and screening tool. J Diabetes Sci Tech. 2009;3(4):722-726.

17. Yang Q, Liu T, Valdez R, Moonesinghe R, Khoury MJ. Improvements in ability to detect undiagnosed diabetes by using information on family history among adults in the United States. Am J Epidemiol. 2010; 171(10):1079-1089.

18. Buijsse B, Simmons RK, Griffin SJ, Schulze MB. Risk assessment tools for identifying individuals at risk of developing type 2 diabetes. Epidemiol Rev. 2011;33(1):46-62.

19. Wilson PW, Meigs JB, Sullivan L, Fox CS, Nathan DM, D'Agostino RB Sr. Prediction of incident diabetes mellitus in middle-aged adults: the Framingham Offspring Study. Arch Intern Med. 2007;167(10):1068-1074.

20. Hivert MF, Jablonski KA, Perreault L, et al; DIAGRAM Consortium; Diabetes Prevention Program Research Group. Updated genetic score based on 34 confirmed type 2 diabetes Loci is associated with diabetes incidence and regression to normoglycemia in the diabetes prevention program. Diabetes. 2011;60(4):1340-1348.

21. Meigs JB, Shrader P, Sullivan LM, et al. Genotype score in addition to common risk factors for prediction of type 2 diabetes. $N$ Engl J Med. 2008;359(21):2208-2219. 
22. Vassy JL, Dasmahapatra P, Meigs JB, et al. Genotype prediction of adult type 2 diabetes from adolescence in a multiracial population. Pediatrics. 2012;130(5):e1235-e1242.

23. Lyssenko V, Jonsson A, Almgren P, et al. Clinical risk factors, DNA variants, and the development of type 2 diabetes. $N$ Engl J Med. 2008;359(21):2220-2232.

24. Cox AJ, Hsu FC, Ng MC, et al. Genetic risk score associations with cardiovascular disease and mortality in the Diabetes Heart Study. Diabetes Care. 2014;37(4):1157-1164.

25. Mühlenbruch K, Jeppesen C, Joost HG, Boeing H, Schulze MB. The value of genetic information for diabetes risk prediction - differences according to sex, age, family history and obesity. PLOS ONE. 2013;8(5):e64307.

26. Schulze MB, Weikert C, Pischon T, et al. Use of multiple metabolic and genetic markers to improve the prediction of type 2 diabetes: the EPIC-Potsdam Study. Diabetes Care. 2009;32(11):2116-2119.

27. Talmud PJ, Hingorani AD, Cooper JA, et al. Utility of genetic and non-genetic risk factors in prediction of type 2 diabetes: Whitehall II prospective cohort study. BMJ. 2010;340(jan14 1):b4838.

28. Hornbak M, Allin KH, Jensen ML, et al. A combined analysis of 48 type 2 diabetes genetic risk variants shows no discriminative value to predict time to first prescription of a glucose lowering drug in Danish patients with screen detected type 2 diabetes. PLOS ONE. 2014;9(8):e104837.

29. Walford GA, Porneala BC, Dauriz M, et al. Metabolite traits and genetic risk provide complementary information for the prediction of future type 2 diabetes. Diabetes Care. 2014;37(9):2508-2514.

30. Shigemizu D, Abe T, Morizono T, et al. The construction of risk prediction models using GWAS data and its application to a type 2 diabetes prospective cohort. PLoS ONE. 2014;9(3):e92549.

31. Hamburg MA, Collins FS. The path to personalized medicine. $N$ Engl J Med. 2010;363(4):301-304.

32. McBride CM, Koehly LM, Sanderson SC, Kaphingst KA. The behavioral response to personalized genetic information: will genetic risk profiles motivate individuals and families to choose more healthful behaviors? Annu Rev Public Health . 2010;31(1):89-103.

33. Calsbeek H, Morren M, Bensing J, Rijken M. Knowledge and attitudes towards genetic testing: a two year follow-up study in patients with asthma, diabetes mellitus and cardiovascular disease. J Genet Couns 2007;16(4):493-504

34. Haga SB, Barry WT, Mills R, et al. Public knowledge of and attitudes toward genetics and genetic testing. Genet Test Mol Biomarkers. 2013;17(4):327-335.

35. Cameron LD, Sherman KA, Marteau TM, Brown PM. Impact of genetic risk information and type of disease on perceived risk, anticipated affect, and expected consequences of genetic tests. Health Psychol. 2009;28(3): 307-316.

36. Vassy JL, Donelan K, Hivert MF, Green RC, Grant RW. Genetic susceptibility testing for chronic disease and intention for behavior change in healthy young adults. J Community Genet. 2013;4(2):263-271.

37. Grant RW, Hivert M, Pandiscio JC, Florez JC, Nathan DM, Meigs JB. The clinical application of genetic testing in type 2 diabetes: a patient and physician survey. Diabetologia. 2009;52(11):2299-2305.

38. Cho AH, Killeya-Jones LA, O'Daniel JM, et al. Effect of genetic testing for risk of type 2 diabetes mellitus on health behaviors and outcomes: study rationale, development and design. BMC Health Serv Res. 2012;12(1):16.

39. Vorderstrasse AA, Cho A, Voils CI, Orlando LA, Ginsburg GS. Clinical utility of genetic risk testing in primary care: the example of Type 2 diabetes. Pers Med. 2013;10(6):549-563.

40. Wijdenes-Pijl M, Dondorp WJ, Timmermans DR, Cornel MC, Henneman L. Lay perceptions of predictive testing for diabetes based on DNA test results versus family history assessment: a focus group study. BMC Public Health. 2011;11(1):535.

41. Vassy JL, O'Brien KE, Waxler JL, et al. Impact of literacy and numeracy on motivation for behavior change after diabetes genetic risk testing. Med Decis Making. 2012;32(4):606-615.
42. Lautenbach DM, Christensen KD, Sparks JA, Green RC. Communicating genetic risk information for common disorders in the era of genomic medicine. Annu Rev Genomics Hum Genet. 2013;14(1):491-513.

43. National Society of Genetic Counselors. What Is Genetic Counseling? Chicago, IL: National Society of Genetic Counselors. Available from: http://nsgc.org/p/cm/ld/fid=43. Accessed September 22, 2014.

44. Haga SB, Barry WT, Mills R, et al. Impact of delivery models on understanding genomic risk for type 2 diabetes. Public Health Genomics. 2014;17(2):95-104.

45. Grant RW, O’Brien KE, Waxler JL, et al. Personalized genetic risk counseling to motivate diabetes prevention: a randomized trial. Diabetes Care. 2013;36(1):13-19.

46. Waxler JL, O'Brien KE, Delahanty LM, et al. Genetic counseling as a tool for type 2 diabetes prevention: a genetic counseling framework for common polygenetic disorders. J Genet Couns. 2012;21(5): 684-691.

47. Cho A, Vorderstrasse A, Suchindran S, et al. Preliminary 3-month outcomes of a study of genetic risk testing for type 2 diabetes in primary care settings. Society of General Internal Medicine Annual Meeting May 7, 2012; Orlando, FL.

48. Voils CI, Coffman CJ, Edelman D, et al. Examining the impact of genetic testing for type 2 diabetes on health behaviors: study protocol for a randomized controlled trial. Trials. 2012;13(1):121.

49. Godino JG, van Sluijs EM, Marteau TM, Sutton S, Sharp SJ, Griffin SJ. Effect of communicating genetic and phenotypic risk for type 2 diabetes in combination with lifestyle advice on objectively measured physical activity: protocol of a randomised controlled trial. BMC Public Health. 2012;12(1):444.

50. Vorderstrasse AA, Ginsburg GS, Kraus WE, Maldonado MC, Wolever RQ. Health coaching and genomics-potential avenues to elicit behavior change in those at risk for chronic disease: protocol for personalized medicine effectiveness study in air force primary care. Glob Adv Health Med. 2013;2(3):26-38.

51. Nishigaki M, Tokunaga-Nakawatase Y, Nishida J, Kazuma K. The effect of genetic counseling for adult offspring of patients with type 2 diabetes on attitudes toward diabetes and its heredity: a randomized controlled trial. J Genet Couns. 2014;23(5):762-769.

52. American Diabetes Association. Standards of medical care in diabetes 2014. Diabetes Care. 2014;37(S1)(Suppl 1):S14-S80

53. Bozkurt O, de Boer A, Grobbee DE, Heerdink ER, Burger H, Klungel OH. Pharmacogenetics of glucose-lowering drug treatment: a systematic review. Mol Diagn Ther. 2007;11(5):291-302.

54. Hoerger TJ, Segel JE, Gregg EW, Saaddine JB. Is glycemic control improving in US adults? Diabetes Care. 2008;31(1):81-86.

55. Wing RR, Hamman RF, Bray GA, et al; Diabetes Prevention Program Research Group. Achieving weight and activity goals among diabetes prevention program lifestyle participants. Obes Res. 2004;12(9): 1426-1434.

56. Delahanty LM, Peyrot M, Shrader PJ, Williamson DA, Meigs JB, Nathan DM; DPP Research Group. Pretreatment, psychological, and behavioral predictors of weight outcomes among lifestyle intervention participants in the Diabetes Prevention Program (DPP). Diabetes Care. 2013;36(1):34-40.

57. Drugs for type 2 diabetes. Treat Guidel Med Lett. 2014;12(139): $17-24$.

58. Distefano JK, Watanabe RM. Pharmacogenetics of anti-diabetes Drugs. Pharmaceuticals (Basel). 2010;3(8):2610-2646.

59. Maruthur NM, Gribble MO, Bennett WL, et al. The pharmacogenetics of type 2 diabetes: a systematic review. Diabetes Care. 2014;37(3): $876-886$.

60. Maruthur NM, Gribble MO, Bennett WL, et al. The pharmacogenetics of type 2 diabetes: a systematic review. Diabetes Care. 2014;37(3): 876-886.

61. Becker ML, Visser LE, Trienekens PH, Hofman A, van Schaik RH, Stricker BH. Cytochrome P450 2C9 *2 and *3 polymorphisms and the dose and effect of sulfonylurea in type II diabetes mellitus. Clin Pharmacol Ther. 2008;83(2):288-292. 
62. Shon JH, Yoon YR, Kim KA, et al. Effects of CYP2C19 and CYP2C9 genetic polymorphisms on the disposition of and blood glucose lowering response to tolbutamide in humans. Pharmacogenetics. 2002;12(2): 111-119.

63. Kirchheiner J, Brockmöller J, Meineke I, et al. Impact of CYP2C9 amino acid polymorphisms on glyburide kinetics and on the insulin and glucose response in healthy volunteers. Clin Pharmacol Ther. 2002;71(4):286-296.

64. Zhang Y, Si D, Chen X, et al. Influence of CYP2C9 and CYP2C19 genetic polymorphisms on pharmacokinetics of gliclazide MR in Chinese subjects. Br J Clin Pharmacol. 2007;64(1):67-74.

65. Zhou K, Donnelly L, Burch L, et al. Loss-of-function CYP2C9 variants improve therapeutic response to sulfonylureas in type 2 diabetes: a Go-DARTS study. Clin Pharmacol Ther. 2010;87(1):52-56.

66. Kang ES, Park SY, Kim HJ, et al. Effects of Pro12Ala polymorphism of peroxisome proliferator-activated receptor gamma2 gene on rosiglitazone response in type 2 diabetes. Clin Pharmacol Ther. 2005;78(2): 202-208.

67. Hsieh MC, Lin KD, Tien KJ, et al. Common polymorphisms of the peroxisome proliferator-activated receptor-gamma (Pro12Ala) and peroxisome proliferator-activated receptor-gamma coactivator-1 (Gly482Ser) and the response to pioglitazone in Chinese patients with type 2 diabetes mellitus. Metabolism. 2010;59(8):1139-1144.

68. Shu Y, Sheardown SA, Brown C, et al. Effect of genetic variation in the organic cation transporter 1 (OCT1) on metformin action. J Clin Invest. 2007;117(5):1422-1431.

69. Zhou K, Donnelly LA, Kimber CH, et al. Reduced-function SLC22A1 polymorphisms encoding organic cation transporter 1 and glycemic response to metformin: a GoDARTS study. Diabetes. 2009;58(6): 1434-1439.

70. Jablonski KA, McAteer JB, de Bakker PI, et al; Diabetes Prevention Program Research Group. Common variants in 40 genes assessed for diabetes incidence and response to metformin and lifestyle intervention in the diabetes prevention program. Diabetes. 2010;59(10):2672-2681.

71. Todd JN, Florez JC. An update on the pharmacogenomics of metformin: progress, problems and potential. Pharmacogenomics. 2014;15(4):529-539.

72. Pfizer, Inc. Glucotrol ${ }^{\circledR}$ (glipizide) Drug Labeling. Revised May 2010. Available from: http://www.accessdata.fda.gov/drugsatfda_docs/ label/2011/017783s0211bl.pdf. Accessed September 22, 2014.
73. Pfizer, Inc. Glynase ${ }^{\circledR}$ PresTab ${ }^{\circledR}$ (glyburide) Drug labeling. Revised October 2013. Available from: http://www.accessdata.fda.gov/drugsatfda_docs/ label/2013/020051s0201bl.pdf. Accessed September 22, 2014.

74. Pfizer, Inc. Diabinese ${ }^{\circledR}$ (chlorpropamide) Drug Labeling. Revised July 2010. Available from: http://www.accessdata.fda.gov/drugsatfda_docs/ label/2011/011641s066lbl.pdf. Accessed September 22, 2014.

75. Corella D, Carrasco P, Sorlí JV, et al. Mediterranean diet reduces the adverse effect of the TCF7L2-rs7903146 polymorphism on cardiovascular risk factors and stroke incidence: a randomized controlled trial in a high-cardiovascular-risk population. Diabetes Care. 2013;36(11): 3803-3811.

76. Huggins GS, Papandonatos GD, Erar B, et al; Genetics Subgroup of the Action for Health in Diabetes (Look AHEAD) Study. Do genetic modifiers of high-density lipoprotein cholesterol and triglyceride levels also modify their response to a lifestyle intervention in the setting of obesity and type-2 diabetes mellitus?: The Action for Health in Diabetes (Look AHEAD) study. Circ Cardiovasc Genet. 2013;6(4):391-399.

77. Delahanty LM, Pan Q, Jablonski KA, et al; Diabetes Prevention Program Research Group. Genetic predictors of weight loss and weight regain after intensive lifestyle modification, metformin treatment, or standard care in the Diabetes Prevention Program. Diabetes Care. 2012;35(2):363-366.

78. Florez JC, Jablonski KA, Bayley N, et al; Diabetes Prevention Program Research Group. TCF7L2 polymorphisms and progression to diabetes in the Diabetes Prevention Program. $N$ Engl J Med. 2006;355(3): 241-250.

79. Johansen Taber KA, Dickinson BD, Wilson M. The promise and challenges of next-generation genome sequencing for clinical care. JAMA Intern Med. 2014;174(2):275-280.

80. Patel CJ, Sivadas A, Tabassum R, et al. Whole genome sequencing in support of wellness and health maintenance. Genome Med. 2013;5(6):58

81. Ashley EA, Butte AJ, Wheeler MT, et al. Clinical assessment incorporating a personal genome. Lancet. 2010;375(9725):1525-1535.

82. Slomko H, Heo HJ, Einstein FH. Minireview: Epigenetics of obesity and diabetes in humans. Endocrinology. 2012;153(3):1025-1030.

83. Bramswig NC, Kaestner KH. Epigenetics and diabetes treatment: an unrealized promise? Trends Endocrinol Metab. 2012;23(6): 286-291.
The Application of Clinical Genetics

\section{Publish your work in this journal}

The Application of Clinical Genetics is an international, peer-reviewed open access journal that welcomes laboratory and clinical findings in the field of human genetics. Specific topics include: Population genetics; Functional genetics; Natural history of genetic disease; Management of genetic disease; Mechanisms of genetic disease; Counseling and ethical

\section{Dovepress}

issues; Animal models; Pharmacogenetics; Prenatal diagnosis; Dysmorphology. The manuscript management system is completely online and includes a very quick and fair peer-review system, which is all easy to use. Visit http://www.dovepress.com/testimonials.php to read real quotes from published authors. 